\title{
The Meniscofemoral Ligament Mimicking a Lateral Meniscus Tear
}

\author{
Bong Keun Park, MD, Hohyoung Lee, MD, Seong-Tae Kim, MD, and Min Geun Yoon, MD \\ Department of Orthopedic Surgery and Traumatology, Cheju Halla General Hospital, Jeju, Korea
}

\begin{abstract}
A 58-year-old male patient who had developed left knee pain with a history of trauma was referred to our hospital. Physical examination and further examination by magnetic resonance imaging revealed results that closely resemble a horizontal tear of the lateral meniscus and a tear of the medial meniscus. Arthroscopically, we found a cord-like structure originating from the posterior $1 / 3$ portion of the lateral meniscus and passing obliquely toward the medial femoral condyle in front of the posterior cruciate ligament without a tear of the lateral meniscus. In this report, we describe a rare case of anterior meniscofemoral ligament that was clearly seen on arthroscopy and mimicked a meniscal tear, which is also known as a pseudo-tear of the meniscus.
\end{abstract}

Keywords: Knee, Ligament, Meniscofemoral, Tear, Meniscus

As reported by Sanders et al. ${ }^{1)}$, it is challenging for arthroscopic surgeons to differentiate a normal variant of the meniscofemoral ligament from a tear of the lateral meniscus or loose body formed by an intra-articular avulsed osteochondral or meniscal fragment ${ }^{2}$. Because of its radiological appearance mimicking a pathologic tear of the meniscus or an osteochondral lesion, it is estimated that numerous patients with meniscofemoral ligaments have undergone arthroscopic procedures that was essentially unnecessary. We report a rare case of meniscofemoral ligament that was clearly seen on arthroscopy preoperatively and mimicked a lateral meniscal tear, which is also known as a pseudo-tear of the meniscus.

Received June 23, 2016; Revised July 26, 2016;

Accepted August 16, 2016

Correspondence to: Hohyoung Lee, MD

Department of Orthopedic Surgery and Traumatology, Cheju Halla

General Hospital, 65 Doryeong, Jeju 63127, Korea

Tel: +82-64-740-5140, Fax: +82-64-743-3110

E-mail: mdleeho@hanmail.net

This is an Open Access article distributed under the terms of the Creative Commons Attribution Non-Commercial License (http://creativecommons.org/licenses/by-nc/4.0/) which permits unrestricted non-commercial use, distribution, and reproduction in any medium, provided the original work is properly cited.

\section{Case Report}

A 58-year-old male patient presented with left knee lateral pain after a slip down injury a month ago. He had a history of ligamentous injury that occurred 20 years ago, for which no further diagnosis or treatment was done. He had been experiencing mild 'giving way' symptoms since then, but the symptom aggravated after the recent trauma. On the physical examination, we found that the range of motion of the patient's left knee was normal. Medial joint line tenderness was present. The result of the posterior drawer test was grade 2 positive, and McMurray test was also positive-knee pain in external rotation. Plain X-ray showed unremarkable findings.

On magnetic resonance imaging (MRI), a longitudinal tear of the medial meniscus (Fig. 1A) and a horizontal tear of the lateral meniscus (Fig. 1B) were shown with high-intensity signal on the proton density spectral presaturation inversion recovery coronal image. There was also a slightly high-intensity signal shown in the posterior cruciate ligament (PCL), indicating a probable acute partial tear of the ligament or evidence of an old injury.

For diagnostic arthroscopy, we made an anterolateral portal for visualization and an anteromedial portal for performing surgery. By examining the intercondylar notch and articular surfaces of the femur and tibia through these portals, we arthroscopically confirmed a longitudinal tear of the medial meniscus but the 

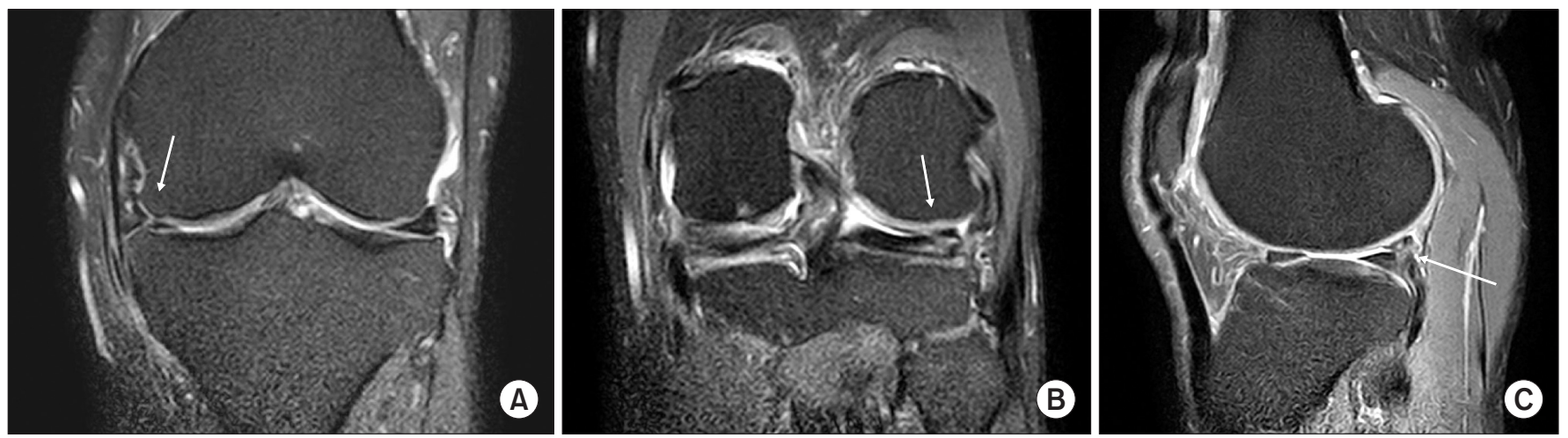

Fig. 1. Coronal proton density spectral presaturation inversion recovery magnetic resonance imaging scans showing high-intensity signal that resembles a tear of the medial (A) and lateral (B, C) menisci, respectively.
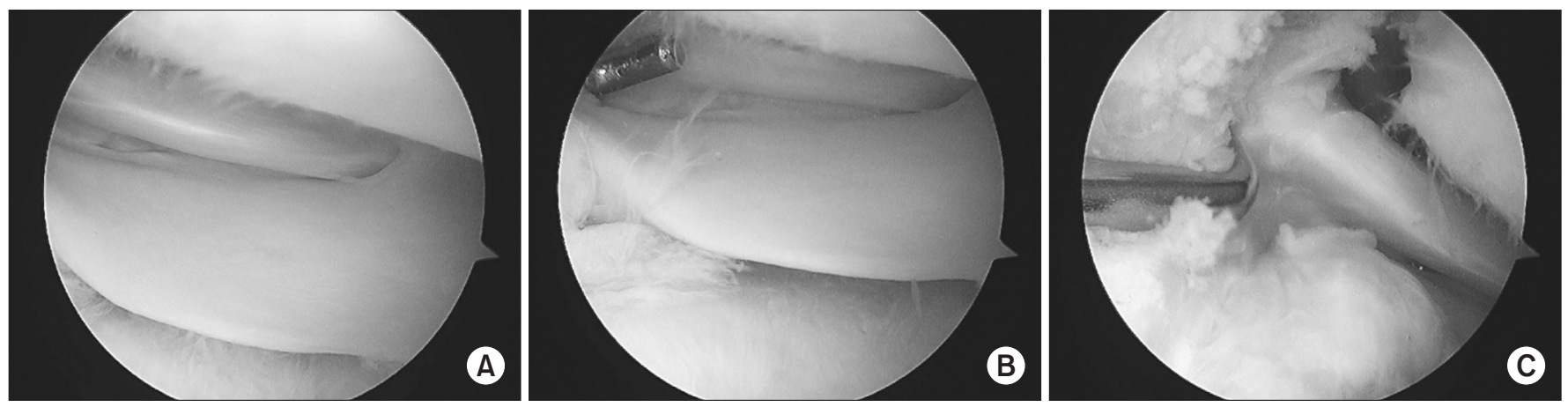

Fig. 2. Arthroscopic views of the left knee show a cord-like structure originating from the posterior horn of the lateral meniscus (A, B) and inserting into the lateral side of the medial femoral condyle. (C) Arthroscopic views from the anteromedial portal (A, B) and from the anterolateral portal (C).

lateral meniscus was intact without tear. Instead, we confirmed a cord-like structure, originating from the posterior $1 / 3$ portion of the lateral meniscus and passing obliquely toward the medial femoral condyle in front of the PCL-anterior meniscofemoral ligament (ligament of Humphrey) (Fig. 2). There was no sign of a tear of the anterior cruciate ligament and PCL structures. The main cause of the knee pain was finally proven to be due to the medial meniscus tear because there was neither a lateral meniscus tear nor a PCL injury in this patient.

Arthroscopic partial medial meniscectomy was performed, and at the 1-year follow-up, the patient could perform daily activities without any discomfort.

\section{Discussion}

We reported a rare case of meniscofemoral ligament that was mimicking a tear of the lateral meniscus on preoperative arthroscopy. According to Watanabe et al. ${ }^{2}, 32.5 \%$ of the meniscofemoral ligaments were present with Wrisberg ligament and 33\% were present with Humphrey ligament and seen either as a discrete low signal-intensity bulge or a lump along the concave surface of the PCL or as a small, ovoid, low signal intensity focus just anterior to the PCL. In a study performed by Bintoudi et al. ${ }^{3)}$, only 81 among 500 patients (37\%) presented both meniscofemoral ligaments and in other studies of Moran et al. ${ }^{4)}$ and Lee et al. ${ }^{5}$, the percentage was $28 \%$ and $1 \%$, respectively. Erbagci et al. ${ }^{6}$ did not reveal the incidence. These studies show variations of the anatomy of meniscofemoral ligaments and the low incidences of meniscofemoral ligaments. In our institution, the meniscofemoral ligament was observed in one individual, which was clearly confirmed by arthroscopy.

In our case, we initially thought the ligament of Humphrey (anterior meniscofemoral ligament) was combined with a tear of the lateral meniscus showing high-intensity signals that extend along the ligament of Humphrey on both coronal and sagittal MRI images (Fig. 3). However, in diagnostic arthroscopy, there was no tear on the lateral meniscus and instead we could clearly confirm the presence of the anterior meniscofemoral ligament originating from the posterior horn of the lateral meniscus and obliquely inserting into the medial femoral condyle. 

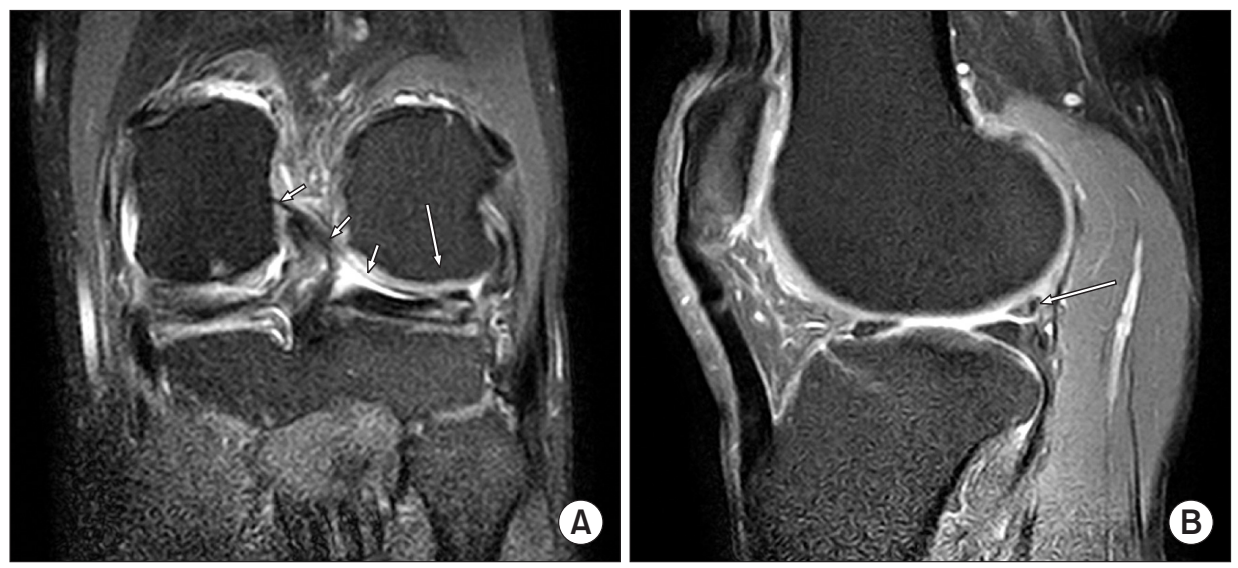

Fig. 3. (A) The ligament of Humphrey (anterior meniscofemoral ligament) was observed as a thin, linear band, with lowsignal intensity on coronal magnetic resonance imaging (short arrows). (A, B) Highintensity signal extending to the ligament of Humphrey mimicking a tear of the lateral meniscus (long arrows).

So arthroscopy surgeons should take meniscofemoral ligaments into consideration and pay close attention to the confusing radiological features when encountering patients with meniscal tears. In addition, it is advised to inform the patients of the possibility of the presence of meniscofemoral ligaments before surgery.

Although meniscofemoral ligaments are not commonly or feasibly seen structures as shown in previous studies, the meniscofemoral ligament itself can be observed during a diagnostic arthroscopic procedure using methods developed by many orthopedic surgeons ${ }^{7,8)}$.

In many biomechanical studies including the research performed by Amis et al. ${ }^{9}$, it has been reported that the meniscofemoral ligament plays a great role after PCL injury. Therefore, it is important to distinguish actual hypertrophy after a PCL injury from congenital abnormality.

In our case, the patient had a history of knee trauma several decades ago but the PCL injury was undiagnosed at that time. On physical examination and preoperative MRI, there was a possibility of PCL injury; however, it was unclear whether the injury resulted from the recent trauma or the remnant of the old neglected injury. Ultimately, the PCL was confirmed to be intact in the patient. So we thought that the variant of the meniscofemoral ligament, which was clearly seen in our case, was more likely to be congenital abnormality rather than hypertrophy after a PCL injury.

The clinical relevance of this report is that normal variants of anatomical structures of the meniscofemoral ligaments may be mimicking tears of the lateral meniscus on MRI but they are actually intact on arthroscopy. Also, as we have seen in our case, the patient initially did not show signs of lateral meniscus tears in physical examination-no pain in the knee in internal rotation during McMurray test and no lateral joint line tenderness. The tear of the lateral meniscus was prediagnosed through MRI before the arthroscopic procedure. So we would emphasize the importance of preoperative physical examination and comparison of the results with radiological findings to reduce the risk of misdiagnosis in meniscal tears.

\section{Conflict of Interest}

No potential conflict of interest relevant to this article was reported.

\section{References}

1. Sanders TG, Linares RC, Lawhorn KW, Tirman PF, Houser C. Oblique meniscomeniscal ligament: another potential pitfall for a meniscal tear: anatomic description and appearance at MR imaging in three cases. Radiology. 1999;213:213-6.

2. Watanabe AT, Carter BC, Teitelbaum GP, Bradley WG Jr. Common pitfalls in magnetic resonance imaging of the knee. J Bone Joint Surg Am. 1989;71:857-62.

3. Bintoudi A, Natsis K, Tsitouridis I. Anterior and posterior meniscofemoral ligaments: MRI evaluation. Anat Res Int. 2012;2012:839724.

4. Moran CJ, Poynton AR, Moran R, Brien MO. Analysis of meniscofemoral ligament tension during knee motion. Arthroscopy. 2006;22:362-6.

5. Lee BY, Jee WH, Kim JM, Kim BS, Choi KH. Incidence and significance of demonstrating the meniscofemoral ligament on MRI. Br J Radiol. 2000;73:271-4.

6. Erbagci H, Yildirim H, Kizilkan N, Gumusburun E. An MRI study of the meniscofemoral and transverse ligaments of the knee. Surg Radiol Anat. 2002;24:120-4.

7. Gupte CM, Bull AM, Atkinson HD, Thomas RD, Strachan RK, Amis AA. Arthroscopic appearances of the menisco- 
femoral ligaments: introducing the "meniscal tug test". Knee Surg Sports Traumatol Arthrosc. 2006;14:1259-65.

8. Lee BJ, Kyung HS, Yoon SD. Anterolateral meniscofemoral ligament with congenital aplasia of the anterior cruciate ligament: a case report. Arthrosc Orthop Sports Med. 2015;2:
120-3.

9. Amis AA, Bull AM, Gupte CM, Hijazi I, Race A, Robinson JR. Biomechanics of the PCL and related structures: posterolateral, posteromedial and meniscofemoral ligaments. Knee Surg Sports Traumatol Arthrosc. 2003;11:271-81. 